\title{
Assessment of Standards for Inter-organizational Tracking Information Exchange in the Supply Chain
}

\author{
Kary Främling, Ville Hinkka, Sagar Parmar, Jaakko Tätilä \\ Aalto University, School of Science, PO Box 15500, FI-02015 AALTO, Finland \\ (e-mail:firstname.lastname@aalto.fi)
}

\begin{abstract}
With increasing globalization and loosely-coupled business relations between different companies, the importance of information exchange standards is increasing. GS1's Electronic Product Code Information Services (EPCIS) is currently one of the main standards proposed for interorganizational data exchange for trace and track purposes in the supply chain. However, some parts of the EPCIS framework are yet to be defined and the standard has to overcome some obstacles to be used as a global standard for trace and track applications. This paper tries to address the main question whether EPCIS has the potential to 'take off' as a globally accepted data-exchange standard.
\end{abstract}

Keywords: Track and trace, supply chain management, inter-organizational data exchange, interoperability, EPCIS.

\section{INTRODUCTION}

Supply chains are getting increasingly geographically spread and loosely coupled, which signifies that they need to be able to set up new supplier relationships at a higher pace than before. Concepts used for this kind of loosely coupled supply chains are Virtual Enterprises and Extended Enterprises. Loose coupling is particularly challenging for interorganizational data exchange, which still today often requires long and expensive setup of Electronic Data Interchange (EDI) communication. Even after EDI integration, supply chains have great challenges in implementing fundamental operations such as tracking shipments and deliveries, as well as handling after-sales and service operations on product individuals. The advance shipping notice (ASN) in EDI is the message that gets the closest to shipment tracking but it is not suitable and intended for shipment tracking. This is why most shipment tracking systems are organization specific, such as those provided by companies like FedEx, UPS etc.

In order to implement shipment tracking, after-sales and service operations on product individuals, it is necessary to identify them as individual instances rather than just belonging to some product category. Company-specific tracking or serial numbers are currently the most used identifiers for product individuals. However, due to their company-specific nature, they are not suited for interorganizational data exchange. Advances in radio frequency identification (RFID) technology, as well as the decreasing cost of implementing that technology, has opened up completely new possibilities for tracking shipment and product individuals. RFID supports product individual-level identification "by definition".

The use of RFID tags and product individual-level identification in general creates challenges for existing supply chain management information systems. As an answer to those challenges, EPCglobal and GS1 are promoting an information system framework that is called the EPC network (EPCglobal, 2005). EPCIS is the standard proposed for interorganizational data exchange in the EPC network. When considering the background of EPCIS and the maturity of the standard, one would expect that it would by now be universally used for tracking items in inter-organizational settings. However, it seems like it is far from being so in reality. The main research question set out for this paper is to what extent EPCIS is being used in reality, as well as identifying the main application domains in which it is used. The main objective of the paper is to analyze and understand the reasons for which EPCIS has not yet become universally used, as well as if and when it eventually will become universally used.

After this introduction, the paper provides an overview of inter-organizational data exchange and EPCIS. Then we provide an overview of different domains where EPCIS has been used to some extent and identify three domains that are of particular interest due to their relatively advanced state regarding inter-organizational data exchange and experiences from using EPCIS. The level of use of EPCIS is analyzed in detail for the selected domains, followed by conclusions.

\section{BACKGROUND}

The classic example of an inter-organizational data exchange standard is EDI (Emmelhainz, 1990; Damsgaard \& Truex, 2000). The best known and most widely used EDI-standards are ANSI X.12 (mainly in the US) and EDIFACT (developed by UN, intended as a global standard) (Nurmilaakso, 2008). EDI standards date back to 1970s and beyond; in the mid1980 EDI use began to expand significantly, following the introduction of the first version of ANSI X.12 in 1981 and the EDIFACT starting from 1985. 
Recently, it has been suggested that newer standards would overcome the challenges of traditional EDI by adding to the syntactic and semantic level of EDI standards. Typically, these standards utilize the power of XML (Extensible Markup Language), dating back to 1996. Besides expressing data, XML defines meta-data, i.e. data on data, through so called tags. Some relatively widely diffused examples of XML-based standards are RosettaNet (Bussler, 2003; Boh et al., 2007) and ebXML (Electronic Business using eXtensible Markup Language).

In this paper we focus on inter-organizational exchange of shipment tracking data, as well as data related to product individuals in general. Our own work in this area started in 2000 with the goal to create systems for implementing the Internet of Things (IoT), which was implemented under the name DIALOG (Distributed information architectures for collaborative logistics). DIALOG was used in multiorganizational and international pilots for tracking shipments and warehouse items in 2002 and 2003 (Holmström et al., 2010). DIALOG was also used and demonstrated for storing and retrieving product individual information in after-sales and maintenance settings, as well as for many kinds of consumer applications. DIALOG has since then mainly been used for product individual lifecycle management applications. We are also involved in a standards initiative called Quantum Lifecycle Management with the Open Group (http://www.opengroup.org/qlm/) for defining information exchange standards for exchanging any kind of product individual data.

It is in this context that we have been following the evolution of EPCglobal standards as a potential candidate for use in our own applications. EPCIS (EPCglobal, 2005) is the standard that is technically closest to the kind of data exchange that we have needed over the years. Unfortunately EPCIS still seems suitable only for SCM but we still think that an analysis of the evolution and the degree of acceptance and use of EPCIS in real applications can provide valuable insight about the actual need and readiness for inter-organizational data exchange, as well as about the challenges related to the launch of standards in this domain.

\subsection{Overview of EPCIS}

The technology and associated computer networks use EPCglobal Network and its EPC Information Services (EPCIS) as an interface to enable EPC-related data to be "captured" and "queried" using defined sets of operations and associated EPC-related standards, combined with security mechanisms that satisfy needs of parties involved. In other words, EPCIS provides a standard interface for storage and access of EPC-related data that can be read and written by authorized parties involved.

An RFID tag attached to a trade item contains a unique electronic product code (EPC) that globally identifies that item while it is in the supply chain. The EPC code would typically be encoded with a Serialized Global Trade Item Number (SGTIN) that contains: The EPC Manager Number (company specific code), Object Class (product number), and
Serial Number for each object tagged. These tags are scanned by readers that send EPC information contained in the tags to EPC middleware. The middleware software filters, collects and stores the information in the EPCIS repository, queries the Object Naming Service (ONS) to find information related to that product and then gets supply chain event data about that product from the EPCIS repository of the parties involved. Access to the EPCIS servers of other trading partners needs authorization and authentication based on predetermined business contracts.

\section{CASE STUDIES}

To illustrate the extent of EPCIS usage and potential challenges for its deployment, authors chose to examine different EPCIS use cases. Firstly, use cases were extensively searched from a variety of sources, including article databases, websites and expert statements. It was found out that the EPCIS standard has been used and "experimented" in many successful pilots such as in Swedish Fisheries (eTracetracefood), in North Sea oil industry (Swedberg, 2008), in Norwegian Meat manufacturing company Nortura (Swedberg, 2011a), by retailer Walmart and in Hongkong baggage handling, to name but a few. Many IT service providers - such as Axway, IBM, Oracle - are also providing EPCIS-based track and trace solutions to customers (Fowler \& Loughead, 2011).

It became evident eventually that use cases - at least with a fully-fledged EPCIS implementation - weren't of ample supply. Thus, three use cases with a relative strong advancement or potential in EPCIS usage were chosen. These three cases are "E-pedigree in pharmaceutical industry", "Railways" and "Technical trade". The former two were chosen due to their apparent advancement and maturity regarding EPCIS relative to other domains. The latter case was chosen because of its potential for a wide-scale use for EPCIS and also because it was a research project in which some of the authors participated, giving a first-hand view on the issues of EPCIS acceptation among customers.

The three chosen cases are analyzed in the following subsections. The structure of the analyses proceeds as follows: Firstly, each case is introduced and its state of RFID deployment is discussed. Thereafter, the use of interorganizational data exchange and EPCIS is analyzed. Finally, challenges are discussed and conclusions drawn.

\subsection{E-Pedigree}

The pharmaceutical industry exhibits one of the most complex supply chains involving many trading partners including manufacturers, repackagers, distributors, third party logistics providers, hospitals, clinics and retail pharmacies. Hundreds and millions of products move through this intricate chain that reduces the transparency of product movement and increases risk in the supply chain. The health care industry is under constant pressure to provide supply prescription drugs to patients safely and securely while reducing costs and improving service levels (Vaczek, 2008). Drug-counterfeiting poses a serious threat to patient safety 
and also harms the image of manufacturers, their profitability and revenue. According to WHO (2006) reports, counterfeit drug business tunes to amount of over US \$35 billion and might reach to US\$75 billion (Suchdeva \& Pati, 2011). To combat this challenge, secured and transparent distribution of drugs between trading partners must be ensured and drug pedigree be captured. Markets such as Turkey, Brazil, France and the US have already begun mandating their manufacturers and distributors to confirm to some sort of ePedigree standards, such as GS1 EPCIS, 2D Datamatrix bar codes, Drug Pedigree Messaging Standards (DPMS), for tracking and tracing purposes (Teichert, 2010). For effective drug identification and traceability, drugs are mass serialized where each drug package is given a unique identification such as an Electronic Product Code (EPC). Matrix codes and RFID tags are used to encode the unique identification and make it machine readable.

\section{RFID Deployment}

The use of RFID tags has not penetrated very far into the healthcare supply chain because of the high cost of tags compared to widely used and economical 2D bar codes (Basta, 2010). The extent of use of RFID tags varies according to the size of the company. Bigger distributors such as McKesson use RFID tags while average size companies like AstraZeneca and Genzyme favour GS1 2D Datamatrix bar codes. Some companies who make biological drugs have chosen to avoid placing RFID tags on their packages out of concern that radio signals involved with RFID tags and readers could possibly modify the effectiveness of their drugs, although recent research studies indicates that this is not the case (Basta, 2010; Swedberg, 2011 b). Other drug manufacturers intend to employ 2D barcodes on the labels they attach to bottles of prescription drugs, and then an RFID tag in addition to bar codes at the case-level. The cost of deployment of RFID tags is higher compared to $2 \mathrm{D}$ bar codes at this point and for companies tagging millions of products every year the incurred cost can be difficult to justify (Basta, 2010).

\section{EPCIS and DPMS}

By early 2000, most trading partners in the pharmaceutical supply chain were sharing basic data of received shipments and payments electronically. This method of sharing data lacked the flexibility and control to identify and track the entry of counterfeit drugs in the supply chain. Many companies in the pharmaceutical supply chain decided to implement track and trace to comply with mandates put forth by different associations such as The European Federation of Pharmaceutical Industries and Associations (EFPIA), California and Florida drug regulation laws. GS1 standards like EPC Information Services (EPCIS) and Drug Pedigree Messaging Standards (DPMS) are widely "experimented" and adopted with satisfactory results in effective tracing and tracking within pharmaceutical supply chain.

The debate on use of the standard whether DPMS or EPCIS, still continues and fails to give a standard that is interoperable and can be implemented by all. Many small manufacturers and distributors have a system of data exchange between trading partners based on DPMS standards (Basta, 2010; SupplyScape, 2008). However, the data shared using this standard are contained in a format that makes it difficult to use the data for other uses. In short, DPMS is not interoperable with other systems and there is a lack of item level serialization in it. These might be the reasons for GS1 to support or favor EPCIS over DPMS standard for data exchange. Also, there has been growing interest amongst IT vendors and pharmaceutical companies to combine DPMS and EPCIS to get the best of both worlds.

A larger group of IT solution providers including IBM, SAP, Axway, and Samsung are supporting and providing solutions for Track and Trace based on the EPCIS standard (Basta, 2010). Axway has been particularly active in promoting the development of EPCIS-based standards for monitoring the pharmaceutical supply chain. A growing number of successful pilots and projects have been carried out using EPCIS. AstraZeneca is using Axway's Track and Trace solution, an EPCIS based application, to meet its product security strategy of enhancing patient safety and protecting brand integrity through serialization of drugs and exchanging data between partners for greater visibility. Axway's solution also meets most of the global compliance regulations of many countries such as Brazil, Turkey, Israel and the US (Teichert, 2010). Other companies are also inclined towards use of EPCIS standards and are in process of negotiations with trading partners for EPCIS and ePedigree transactions.

\section{Challenges}

While there are known examples of successfully implemented systems based on the EPCIS standards on one hand, there are certain obstacles that hold this standard from actually taking off in the pharmaceutical supply chain. Amongst them, inter-organizational data exchange security issues are primary ones. Companies might not be willing to share certain data beyond their boundaries and especially with their competitor. Discovery Services, a standard planned by GS1 to address this issue still needs same parts to be developed and be accepted by all pharmaceutical companies world-wide. Worldwide adoption of the EPCIS standard is a very slow process. Furthermore, an EPCIS system is prone to attacks from the internet and other possible hacking exploits. Attackers or hackers can control servers/databases handling EPCIS information and forge them. This could be a serious security breach for companies and can increase their operational business risk. Systems to tackle these problems need to be improved and developed for the use world-wide. The existence of (at least) two competing standards (EPCIS and DPMS) may also cause confusion regarding which one to choose.

\subsection{Railways}

Railways have been an early domain of RFID usage. Already in the 90's, RFID was applied in railways in several countries in Europe, Asia and Americas (Landt, 2005), and nearly all railcars were RFID tagged in the US by 1994, for example. In Europe, there has also been considerable interest in RFID in railway operations. The main usage has been tagging of 
wagons or locomotives, which enables automated identification and tracking of rolling stock units. With the use of RFID or other advanced tracking systems, arises the question of how to transfer and share the generated tracking information intra- and especially inter-organizationally. The information sharing of tracking information in railways is discussed in this section mostly from the case perspective of Finnish and Swedish railway operations. Both the Finnish and Swedish railway operators and administrators have been early adopters of RFID tracking and have collaborated in their research and design of the systems. The data sources for the case are public documents and four informants in total from the Finnish Traffic Agency (FTA), VR (a state-owned Finnish railway operator) and Swedish Transport Agency (STA).

\section{RFID Deployment}

Enabling and pushing inter-organizational data exchange forward, RFID has been deployed increasingly in the European railway operations. On a higher level, European Commission has published a Technical Specification for Interoperability (TSI) 2006/861/EC regarding rolling stock freight wagon, which specifies RFID air standard ISO180006 type A to be used if RFID is applied (European Union, 2006). This EPC compliant standard has been adopted at least in the Finnish and Swedish railways.

In Finland, VR has recently installed Gen 2 Class 1 EPC compliant RFID tags to all of its cargo wagons (Vilant, 2011). The company intends to use the tags in three different ways: firstly, it has streamlined its own rail yard operations by using hand-held RFID readers to identify wagons and transfer data intra-organizationally; secondly, it will start to track its wagons using the upcoming network of fixed RFID readers to be installed by the Finnish Transport Agency; and thirdly, it has planned to install its own fixed readers to offer its customers tracking data of transportations. Regarding the second point, FTA has planned to start deploying the fixed RFID readers along the Finnish railway network at the end of 2011. The purpose is to install around 120 readers to places where it has rolling stock monitoring sites. FTA will use them to collect data for preventive maintenance use, and identification and measurement data will be distributed to rolling stock owners and maintainers as well.

In Sweden, the RFID deployment isn't necessarily as wide as in Finland but has been planned and designed extensively. Between 2005 and 2008, SJ (Swedish state-owned railway operator) tested RFID systems based on active tags but a satisfactory standard was not found. From then on, they have been piloting RFID with passive EPC tags. The results have been satisfying, and the plans include using the tags with the upcoming fixed RFID reader network installed by the Swedish Traffic Administration. There are currently 10 readers in pilot use between Falköping and Göteborg, and the long-term goal is to install between 500 and 700 readers along the Swedish railway network.

As can be concluded from the Finnish and Swedish RFID implementations, there seems to be a fertile ground for interorganizational data interchange from a technological perspective. EPC compliant RFID tags are used and they have gained a strong position as means of identification. What needs to be considered next is whether there is a demand and willingness to share data between organizations and if so, whether EPCIS is the means to accomplish this goal.

\section{Inter-Organizational Data Exchange}

In Finland, VR uses EDI to exchange inter-organizational data - for instance orders, invoices, transportation documents, tracking data - with its customers. It has also a web application for smaller customers without permanent contracts. There are also prospects for further, richer data interchange if VR begins to install its own fixed readers and offer cargo tracking to its customers, as has been planned. It isn't clear yet if the data provided to customers should be more detailed than just the wagon identification and direction. It could include cargo contents, for example, but then the data content would be more refined than the one in the interest of the FTA's system. The data standard to be used in the exchange of the tracking information of the fixed readers will be ultimately decided by the FTA but it will take into account the needs of other stakeholders, including VR. EPCIS has been brought up in the discussions every now and then but it has not been favored in any way and no decision for the data exchange standard has been made yet.

In Sweden, EPC pilot projects have involved use of EPCIS since the beginning and no other standards have been tested or considered for the data interchange. The 10 fixed readers that are operating currently use EPCIS to share tracking data between the Falköping freight terminal and Göteborg harbor. EPCIS has been regarded to perform well without any major problems.

In summary, stakeholders in both Finnish and Swedish railways exchange data inter-organizationally even without EPCIS. The need for standardizing has been acknowledged as well. However, it still remains unclear which standard will offer the best solution and become dominant. The standard to be used didn't seem to play a big role in the Finnish railways as long as it proved to function properly, according to the informants. The Swedish railways have embraced EPCIS more than the Finnish railways but the benefits over other ways to share data, like EDI, are harder to identify. It has been suggested by the STA that after the installation of the fixed RFID readers along the railway network is finished, it is then the role of markets to use the data provided and develop new services and businesses based on it (Ivansson, 2010). But we argue that this may not happen so easily - at least with EPCIS - if companies don't see a clear benefit in EPCIS over their existing systems. Even VR, who plans to provide RFID based tracking systems to its customers in the future, has not decided the data standard to be used. If they already have a well working EDI infrastructure, it may be hard to justify new implementations based on EPCIS.

\section{Challenges}

Clearly, there is a need for a widely used standard in interorganizational data exchange in railway operations. In 
Swedish railways, for instance, $60-70 \%$ of the wagons come from other European countries (Ivansson \& Andersson, 2011). If standardized messages were transferred between organizations from other countries, there would be big potential for exchange of tracking information. Then again, in the Finnish railways, there are fewer stakeholders and they are a lot less international than in Sweden. Another possible obstacle to a European-wide standard for inter-organizational data exchange is that some countries are already building their own tracking systems in railways according to the informants. This might lead to problems in interoperability. One solution or remedy to this could be that an administrative body would impose the standard to be used. In railways, European Commission could define the standard in its TSI but as for now, there isn't that kind of progress to be seen in the near future, the informants say.

\subsection{Technical Trade}

To spread the use of RFID/EPC technology, GS1 Finland together with two universities launched an exploratory case study project together with 16 companies - 12 manufacturers, 3 wholesalers and one Logistics Service Provider (LSP) acting mainly in technical trade industry and especially in heating, plumbing and air-conditioning (HPAC) field. The main purpose of the project was to find suitable application areas for RFID/EPC technology in the technical trade supply chain and create a roadmap for adopting supply chain -wide RFID/EPC technology implementation.

\section{RFID Deployment}

The project was divided in three phases: (1) Research the applicability of RFID technology for the technical trade industry, (2) test the technology in practice, if RFID turns out to be suitable for the industry, and (3) create a roadmap for promoting the use of RFID to the whole industry.

In the first phase of the project, the participating manufacturer and wholesaler companies found enough benefits in their operations to consider larger RFID tracking implementation. During the second phase, testing, they also found ways to tackle major industry specific problems of adopting RFID tracking, such as ensuring the reading on metal components typical of the industry. After the test, the biggest wholesaling company participating in the project announced that they will start to implement RFID at first to improve their receiving in the second half of 2012. That announcement also gave guidelines for roadmap creation and helped to set concrete targets and milestones for the project participant companies for adopting RFID. This announcement also encourages the participant companies to discuss about practical issues of adoption such as what kind of RFID tagging the wholesalers prefer and what would be the format of Advanced Shipping Notice (ASN) messages that the wholesalers want.

\section{Inter-Organizational Data Exchange}

As GS1 Finland was the coordinator and main initiator of the project, their purpose was to propose technological solutions that were in accordance with global GS1 standards. Some of the managers of GS1 Finland formulated this in the following form at a steering group meeting in the early phase of the project:

"GS1 is not involved in any project that does not support global GS1 standards!”

The companies involved in the project did not express any resistance against the use of EPCIS in their connections, if it works. Because the situation in the beginning of the project was that most of the participant companies did not even use EDI in their connections, and therefore when developing their logistics to apply electronic data messages, they could apply any new standard, as their existing systems need considerable improvements.

\section{Challenges}

When researching the roadmap for industry-wide RFID/EPC implementation, the research team in the project had a problem: Especially GS1 Finland would have liked to recommend implementing EPCIS standards, but they realized that there is no software or integrator company that could provide a ready "EPCIS product". The integrator company, who is market leader in Finland and in Nordic countries in supply chain management RFID implementations, does not at least yet have the ability to offer solutions based on EPCIS. One major Finnish software company has developed an "EPCIS product" in an EU project some time ago, but according to GS1 representatives, it still requires further development to be suitable for implementation in the technical trade industry. Therefore, in the end of the research project GS1 ended up to recommend to use other interface standards widely used in the industry at the moment, but keep EPCIS in mind in a way that the system could be developed in the future to apply EPCIS.

The settings for the project seem to be ideal for applying EPCIS, because there was a strong involvement of GS1 in the project, and the project participant companies did not use any other dominant standard, which they would prefer to rely on. However, project participant companies had to accept that EPCIS is not ready enough for implementation. Therefore GS1 did not want to risk the enthusiasm towards RFID by recommending a standard that is still under development.

\section{CONCLUSIONS}

We started developing systems and interfaces for interorganizational exchange of tracking data in the supply chain because of the clear need for such solutions by companies doing international investment projects in 2001. We have therefore been closely following the evolution and the takeup of such solutions in practice. Despite technical challenges of EPCIS compared to alternative approaches (Främling et al., 2007), we would have expected EPCIS and related standards to become universally used in SCM and similar applications. However, the conclusion of the case studies performed is that EPCIS is still mainly being used on an experimental scale in domain-specific applications. 
From the case studies, we have attempted to identify the main reasons that would explain why EPCIS is not used more universally. We have identified at least the following potential explanations for the phenomenon:

- Companies may not be ready or willing to share information with other organizations. Most RFID success stories are mainly intra-organizational applications, where the use of EPCIS does not provide enough value for the cost that it causes.

- EPCIS is too tightly coupled with RFID and SCMfocused, which makes it hard to extend for use in other parts of business, thereby limiting the potential profits that could be achieved.

- $\quad$ EPCIS is too complex or costly to implement compared to the benefits. Even though validated EPCIS implementations are provided by many software providers, the required implementation and systems integration may still be perceived as being too high.

Further research would be required in order to understand the impact of these causes for the non-use of EPCIS or other information exchange standards. Such an increased understanding might help us to create standards that would be more widely accepted. Since the popularity of RFID started increasing over ten years ago, it has been said that we only need to find the right "silver bullet" that will make RFID and inter-organizational information exchange based on it expand rapidly at some moment. For the moment, we are still waiting for that silver bullet to be found.

\section{REFERENCES}

Basta, N. (2010). Information Technology Serialization Efforts Energize Track-and-Trace Technology. Pharmaceutical Commerce. Accessed 11 October 2011: http://www.pharmaceuticalcommerce.com

Boh, W.F., Soh, C, and Yeo, S. (2007). Standards development and diffusion: A Case Study of RosettaNet. Communications of the ACM, 50, pp. 57-62.

Bussler, C. (2003). B2B Integration: Concepts and Architecture. Springer.

Damsgaard, J. and Truex, D. (2000). Binary trading relations and the limits of EDI standards: The Procrustean bed of standards. European Journal of Information Systems, 9(3), pp. 173-188.

Emmelhainz M.A. (1990), Electronic Data Interchange: Total Management Guide. Van Nostrand Reinhold, New York.

EPCglobal (2005). EPC Information Services (EPCIS) Specification. Accessed 21 September 2011: http://www.gs1.org/gsmp/kc/epcglobal/epcis/epcis_1_0_ 1-standard-20070921.pdf

European Union (2006). Commission decision concerning the technical specification of interoperability relating to the subsystem 'rolling stock - freight wagons' of the transEuropean conventional rail system. Accessed 2 September 2011: http://eurlex.europa.eu/LexUriServ/LexUriServ.do?uri=OJ:L:200 6:344:0001:0467:En:PDF
Fowler, P. and Loughead, K. (2011). Life Sciences Strategies:A Practical Approach to Healthcare Supply Chain Collaboration. Axway White Paper.

Främling, K., Harrison, M., Brusey, J., and Petrow, J. (2007). Requirements on Unique Identifiers for Managing Product Lifecycle Information - Comparison of Alternative Approaches. International Journal of Computer Integrated Manufacturing, 20(7), pp. 715-726.

Holmström, J., Främling, K., and Ala-Risku, T. (2010). The uses of tracking in operations management: Synthesis of a research program. International Journal of Production Economics, 126(2), pp. 267-275.

Ivansson, G. (2010). Radio Frequency Identification for Rail Traffic. Accessed 2 September 2011:

http://www.rfidnet.ch/downloads/1_swedish-railwaypresentationseptember-14-v2-.pdf

Ivansson, G. and Andersson, L. (2011). RFID in Rail', Swedish Transport Administration. Accessed 2 September 2011:

http://www.gs1.se/global/EPC/RFID_in_Rail/Swedish_T ransport_Administration.pdf

Landt, J. (2005). The history of RFID. IEEE Potentials, 24(4), pp. 8- 11 .

Nurmilaakso, J.M. (2008), Adoption of e-business functions and migration from EDI-based to XML-based e-business frameworks in supply chain integration. International journal of production economics, 113(2), pp. 721-733.

Swedberg, C. (2008). EPCIS Technology Improves Visibility for North Sea Oil Service and Supply Companies, RFID Journal. Accessed 1 October 2011: http://www.rfidjournal.com/article/view/4301.

Swedberg, C. (2011a). Norsk Lastbaerer Pool Inserts RFID Into the Norwegian Food Chain, RFID Journal. Accessed 1 October 2011: http://www.rfidjournal.com/article/view/8137

Swedberg, C. (2011b). Researchers Find Biologics Not Harmed by RFID RF Signals. RFID Journal. Accessed 3 November 2011: http://www.rfidjournal.com/article/print/8310

Suchdeva, S. and Pati, D.P. (2011). Leveraging RFID and 2D Barcodes: ePedigree and Beyond. TCS White Paper. viewed on 14 August 2011.

Teichert, E. (2010). Axway to Bolster Patient Safety and Compliance for AstraZeneca. Fierce Pharma, Accessed 11 October 2011: http://www.fiercepharma.com/press_releases/axwaybolster-patient-safety-and-compliance-astrazeneca

Vaczek, D. (2008). Anteing Up for RFID. Pharmaceutical \& Medical Packaging News. Accessed11 October 2011: http://www.pmpnews.com/article/anteing-rfid

SupplyScape (2008). Combining EPCIS with the Drug Pedigree Messaging Standard.

Vilant (2011). VR Transpoint Builds New, Efficient and Multi-Functional Logistics System. Accessed 2 September 2011: http://www.vilant.com/company/blog/2011/05/23/vrtranspoint-builds-new-efficient-and-multi-functionallogistics-system/ 